\title{
SESSION I \\ ADDRESSES
}

PETER G. POLSON, University of Colorado, Presider

\section{Three-dimensional reconstruction of identified nerves in genetically identical animals}

\author{
C. LEVENTHAL \\ Columbia University, New York, New York 10027
}

Computer aided reconstruction by tracing of serial sections (CARTOS) has been used to make three-dimensional drawings of the anatomy of individually identified nerve cells in genetically identical animals. The animals studied reproduce parthenogenetically and are thus genetically equivalent to identical twins. We have studied the optic ganglion of the water flea, Daphnia magna, and several large motoneurons of Poecilia formosa and small tropical fish. (Co-authors Francoise Leventhal and Edwardo Macagno.)

\section{Constructing cognitive environments}

\author{
SEYMOUR PAPERT \\ Massachusetts Institute of Technology, Cambridge, Mossachusetts 02199
}

Developmental psychology is traditionally limited to observing intellectual growth in naturally occurring cognitive environments. Mixed societies of children and computers offer more controlled variation than cross-cultural studies and deeper variation than is usual in experimental psychology. 